\title{
Canadian dairy cattle veterinarian perspectives on calf welfare
}

\author{
C. L. Sumner and M. A. G. von Keyserlingk ${ }^{1}$ \\ Animal Welfare Program, Faculty of Land and Food Systems, University of British Columbia, 2357, Main Mall Vancouver, BC, Canada, V6T 1 Z6
}

\begin{abstract}
As advisors to dairy farmers, veterinarians are ideally positioned to influence the health of the dairy herd. Recent studies have demonstrated that dairy cattle veterinarians are also concerned about animal welfare, specifically on issues related to the housing environment, painful conditions and procedures, and managing disease in adult animals. However, less is known regarding their perspectives on calf welfare. The goal of this study was to engage cattle veterinarians in an in-depth discussion to gain a better understanding of what they think about calf welfare, and to provide clarity on what they feel is their responsibility to improve the welfare of dairy calves. Focus groups $(\mathrm{n}=5)$, that collectively had 33 participants representing 5 Canadian provinces and different geographical regions, were conducted as part of a continuing education workshop for Canadian cattle veterinarians. Two trained individuals undertook exploratory data analysis using applied thematic analysis, where initial themes were identified and used to develop a detailed codebook to further guide the coding process. All transcripts were coded twice to test the validity of the initial codes and themes. Four major themes were identified: (1) veterinarians prioritized calf health and traded off this issue for other issues such as the calf's social needs; additionally, concerns included nutrition, hunger, and bull calf management; (2) veterinarians see their role in improving calf welfare within the context of shifting norms of calf management, believed to be consequence of pressure from within their profession, but also arising from pressure from their clients and the public; (3) veterinarians see their role as one of exerting social influence, primarily as an educator of their clients; and finally, (4) veterinarians see their responsibility in improving calf welfare as shaped by their personal values and professional ethics. Our results indicate that the veterinarians participating in this study are concerned about a range of calf welfare
\end{abstract}

Received April 2, 2018.

Accepted July 4, 2018.

${ }^{1}$ Corresponding author: marina.vonkeyserlingk@ubc.ca issues, believe they should have a more active role in calf management on farms, and see their role in improving calf welfare as shaped by their own values, the needs of their clients, and the concerns of the public.

Key words: focus group, dilemma, professional ethics, social influence

\section{INTRODUCTION}

Efforts to improve dairy cattle welfare have mainly focused on motivating farmer behavior change (Tremetsberger and Winckler, 2015; Ritter et al., 2017). Recently, others have argued that promoting improvements in dairy cattle welfare should consider all relevant social actors who influence the dairy farmer (Ritter et al., 2015; Shortall et al., 2016). Because most dairy farmers consider the veterinarian to be an important advisor for decisions about animal welfare (Friedman et al., 2007; Garforth, 2011; Broughan et al., 2016; Wolf et al., 2016), it is worthwhile to consider the veterinarian's perspective.

The traditional role of the dairy veterinarian has focused on health (Fraser et al., 1997), reproduction (Mee, 2007), and milk production (LeBlanc et al., 2006), but more recent work indicates that dairy cattle veterinarians are also concerned about animal welfare, as it relates to disease (Lastein et al., 2009; Sayers et al., 2014; Shortall et al., 2016), pain (Thomsen et al., 2012; Becker et al., 2013), and housing (Ventura et al., 2015). Ventura et al. (2016b) found that European cattle veterinarians had multidimensional views on animal welfare beyond managing pain and disease, including beliefs that both barriers and solutions to improving welfare included economic concerns and diverse industry stakeholder input.

Veterinarian perspectives about dairy calf welfare are less well studied but include concerns about calf health and nutrition in organic systems (Ellingsen et al., 2012; Duval et al., 2016), disease management (Boersema et al., 2013; Bauman et al., 2016), and managing pain during routine procedures such as dehorning (Misch et al., 2007; Fajt et al., 2011). However, to our knowledge, no in-depth study has assessed the views of Canadian veterinarians regarding calf welfare. 
Table 1. Guided questions (and the reason for asking each question) used by the facilitators during the 1-h focus group ( $\mathrm{n}=5$ ) discussion with Canadian cattle veterinarians on calf welfare

\begin{tabular}{ll}
\hline Question & Reason for asking \\
\hline Q1: What sorts of things do you think are a part of dairy calf welfare? & To identify a range of issues \\
Q2: What responsibility do you think you have in addressing dairy calf welfare? & To identify perceptions of responsibility \\
Q3: What are you currently doing to address these calf welfare issues? & To identify a range of actions \\
Q4: If given the opportunity, what would you change about what you do to address & To identify perception sphere of action/ \\
calf welfare? & influence \\
$\begin{array}{l}\text { Q5: Put yourself in the shoes of the public - what concerns do you think they would } \\
\text { have about the life of a calf on a dairy farm? }\end{array}$ & To offer a different frame of reference \\
\hline
\end{tabular}

Understanding the human element of animal welfare is central to finding solutions that lead to improvements (Lund et al., 2006), and a poor understanding about veterinarian perspectives likely poses barriers toward implementing welfare improvements. The goal of this study was to understand Canadian dairy cattle veterinarian perspectives on improving calf welfare. Guided discussion among peers is one way to help people discuss an underexplored topic (Powell and Single, 1996). Therefore, we asked veterinarians to engage in a guided discussion on dairy calf welfare to provide a better understanding of (1) what veterinarians identify as welfare issues, and (2) what they think is their responsibility to address these issues.

\section{MATERIALS AND METHODS}

\section{Ethics Approval}

This study was approved by the University of British Columbia Behavioral Research Ethics Board (\#H1600421). All participants provided written consent before participation.

\section{Study Site and Participants}

We conducted a 1-h focus group session (organized by both authors) as part of a continuing education workshop for Canadian cattle veterinarians. All participants were given the option of discussing calf welfare in a non-study group (i.e., the discussion would not have been audio-recorded) if they preferred to not participate in the research; however, all consented to participate. A convenience sample of 33 veterinarians participated ( 5 women, 28 men) from 5 Canadian provinces from different geographical regions (Maritimes, eastern provinces, and western provinces). The largest proportion of participants came from Ontario and Quebec, the 2 provinces with the largest number of dairy farms in Canada. One group included a farmer as a participant and this person's contributions were not included in the data analysis. We created 5 focus groups: 1 group of 10 participants exclusively from Québec (French language group), and 4 groups of 6 participants each (English language groups). The English language groups were balanced so that each group had participants from all represented provinces.

\section{Data Collection and Analysis}

Focus group moderators facilitated the discussion using guided questions developed by both authors about veterinarians' perspectives on improving calf welfare. The questions (see Table 1) were modeled on previous work with dairy cattle veterinarians (see Ventura et al., 2016b).

Probing questions (i.e., those seeking clarification or further explanation) were included in the guide to prompt discussion on topics (e.g., social housing or bull calf management) if the participants did not bring them up. All group discussions were audiotaped and transcribed verbatim. The French audio file was first transcribed in French and then translated to English. All transcripts were checked against the raw audio files for fidelity.

Following Guest et al.'s (2014) description of applied thematic analysis, our analytic approach combined exploratory data analysis with the objective of identifying emergent themes based on the research questions outlined in the introduction. First, the primary author and a research assistant independently read each transcript to identify initial themes that emerged by observing the meaning in the text generated by the discussion (Guest et al., 2014). We also identified an initial list of codes, which were labels identifying specific portions of text that illustrated the meanings of the themes. All themes and codes were identified first within individual focus groups and then compared across groups.

Next, the coders met to discuss their lists of initial themes and codes, identifying similarities and differences, and the relationship between these phenomena. We condensed these 2 lists into a single codebook that served as a guide for the remaining coding. The codebook was organized by themes, code labels, and definitions. Under each theme, related codes were hierarchically arranged based on increasing specificity of 
description. This format allowed the coders to visualize the relationship between the specific coded sections of the data and the overall thematic interpretation of the data.

Next, we independently coded all transcripts according to the codebook. This step was iterative, allowing us to add codes not noted in the first step and to refine the organization of the codes under themes based on whether they were referring to a descriptive norm (describing a current animal welfare norm) or injunctive norm (describing what a norm should be; Rimal and Real, 2005). Descriptive norms were distinguished from injunctive norms to clarify what veterinarians currently did to improve calf welfare and what they thought they should do to improve calf welfare. This distinction is further discussed in the beginning of the Results section.

During the third and final step, all transcripts were recoded by both coders and any changes were discussed and included in the codebook. This final coding was done $90 \mathrm{~d}$ after the initial coding to check the validity of interpretation of the data (based on Guest et al., 2014). The final organization of the major themes is reported below. Quotes were chosen as exemplars to illustrate a concept and have been modified for length and clarity. Brackets inserted into quoted text indicate where we have added words to clarify the quote. Attribution of quotes is indicated in parentheses after each quote, with the letter "V" indicating participant and the letter "G" indicating group. Participant and group numbers assigned during data collection have been altered in this article to further protect anonymity.

\section{RESULTS}

Four major themes emerged during data analysis. The first 3 themes are based on descriptive norms of what participants considered were calf welfare concerns, why they think calf management norms are changing, and what they believe is their role in improving calf welfare. The final theme is based on injunctive norms that describe participant narratives regarding their roles and responsibilities in improving calf welfare.

\section{Theme 1: Dairy Cattle Veterinarians' Concerns About Calf Welfare}

Participant descriptions about calf welfare included a variety of calf-based concerns and related management practices, poor prioritization of calf management on farms, and addressing welfare concerns as trade-offs with each other.

Calf Welfare Concerns and Related Management Practices. Participant descriptions of specific calf welfare concerns included health (e.g., disease such as pneumonia and scours, and wet navels on bull calves in the sales barn), affective states (e.g., pain and happiness), and social needs (e.g., social housing). Participants also discussed management practices that contributed to these welfare concerns: housing (e.g., barn hygiene and ventilation), routine health practices (e.g., vaccine and antibiotic use, colostrum management), and providing pain relief during routine procedures (e.g., dehorning) and disease.

In particular, veterinarian concerns about calf welfare included issues such as hunger and inadequate nutrition. Ensuring adequate nutrition for preweaned calves emerged as a central issue in all 5 groups as they discussed problems associated with the amount of milk fed to calves. As one participant offered when describing calf nutrition management, "I think the very first thing I would like to change is just adequate nutrition, because I still think that that's such a big issue on a lot of places." (V1, G5). Veterinarian concerns with nutrition also referred to the perceived level of effort that they see farmers making to ensure calves were drinking the offered milk, as described by one participant, "... from day one, those calves need to be paid proper attention to ... a lot of those calves are [the] last little chore before the end of the day as you rush through, right?... and the calf not drinking [impersonating farmer], 'oh well, I got to go to this event now... [I'll] check in the morning'." (V5, G2). Additionally, participants cited the amount of milk fed to calves as being a root cause for developmental problems: "... we underestimate nutrition; we underfeed our calves. I think it's the start of abnormal pathologies of growth." (V5, G3). Finally, the failure to provide adequate amounts of milk to calves was an issue linked with behavior problems, "... as far as nutrition, ... if a farmer is only feeding two liters of milk to a calf, it spends the rest of the day, as long as it's awake, sucking on anything it can get to because it's so hungry." (V2, G1).

Priorities and Trade-Offs. Veterinarians framed some welfare concerns as a consequence of a failure by both the farmer and the veterinarian to prioritize calves. Participants linked concerns about calf health with how care was delegated to inexperienced employees, as explained by one participant, "... the calves are always pushed onto the hired help ... it's a new person coming through, it's getting them trained and recognizing health events." (V3, G4). Another concern raised by participants was the lack of economic outputs that related poor calf welfare with substandard housing, "... the calves aren't producing milk, so the [lactating] cows get the comfortable stalls and that's where investment is." (V1, G1). Participants also identified concerns within the veterinary clinic, indicating their own culpa- 
bility in calves being a lower priority "... we establish management practices for the herd and we don't include calves." (V3, G3).

Bull calf management was also viewed as a welfare concern and again related to prioritizing. These concerns were almost always explicitly linked to economics. For example, bull calves were characterized as, "... a waste product of a dairy farm." (V4, G5). The quality of bull calf care was considered price-dependent, which then dictated the level of concern, "... If they're worth twenty bucks, they get fed, sort of." (V6, G2). Bull calf problems were also linked to the routine practice of selling them shortly after birth, which shifted the responsibility of care away from the dairy farmer (and arguably the veterinarian) as described by participants in group 2:

Veterinarian 1: "... there's a lot of guys that feel that if they know they're not keeping the bull calves and they don't know where they're going, then [as] soon as that navel's dry or the calf's dry, it's on the truck and gone, right?"

Veterinarian 3: "They might not even really get colostrum."

For issues about calf housing, participants linked 3 different concerns about calf welfare: health, social needs, and hunger. All groups discussed these concerns in terms of trade-offs with one another; for example, participants felt that promoting good calf health came at the cost of socially housing calves. This characterization of trade-offs also indicated that although participants prioritized health and equated good health with individual housing, they were also aware of the social needs of calves, as one participant described, "... it would be great if we can raise calves in a group, for them, but I've personally seen quite a few issues with it for other reasons, disease-wise." (V1, G5). Participants who addressed both calf health and social concerns saw this as finding a compromise between the two, "... you want a bit of social aspect for the calf, but then you don't want to jeopardize its health, so you got to kind of make something work that's in the middle." (V2, G4).

Managing milk allowances within a social group created some concerns for participants because of challenges associated with competition and poor hygiene when using automated calf feeders. That said, participants also felt that automated calf feeders facilitated socially housing calves and addressed the problem of underfeeding milk, but these positive attributes of social housing were almost always discussed at the cost of health, particularly when it came to maintaining hygiene, as one participant described, "... automatic calf feeders, you know that's the solution to ... giving more milk ... but on the disinfection side it's often ... people think that everything will get done by itself and the disinfection doesn't happen." (V3, G3).

\section{Theme 2: The Shifting Norms of Calf Management Practices}

Participants described how the norms of calf management practices were changing but specifically distinguished between pressures driving change as either external or internal to the dairy industry.

External Pressures to Change. Participants linked shifting norms of calf management practices with public perceptions of calf welfare. All groups discussed early separation of the cow and calf after birth (cowcalf separation) as a primary public concern. Additional public concerns included individual housing; bull calf management; painful procedures such as dehorning, castration, and extra teat removal; nutrition; health and hygiene; and mortality. Public concerns were attributed to a lack of education about dairy farming and romanticism of traditional farming imagery. At times, these concerns were viewed as understandable, as one participant stated that public concerns about cow-calf separation were, "totally logical ... because ... they [the public] don't see the same things we do." (V9, G3). However, the perception about the public's lack of education about dairy farming also fueled participants' justifications of cow-calf separation because the public does not, "... realize that for the health and welfare of the calf, it [cow-calf separation] is probably one of the best things you can do." (V4, G1). Veterinarians repeatedly claimed to support cow-calf separation to facilitate management practices that they perceived improved calf health (i.e., hand-feeding colostrum to calves and individually housing calves) and, for some, this practice was also important so that the cow could join the lactating herd after the birth of the calf. Participants credited anthropomorphic perceptions of the mother-offspring relationship as a reason for the public's perceptions of calf welfare because, "... they've had a kid and they couldn't imagine someone taking their kid away from them when it was born." (V2, F4).

Participants discussed how educational efforts such as farm visits or increased agricultural education in schools could address public concerns. As one participant explained, "I think you can explain to the public why [the calves] don't stay with mum fairly well. And most people, if you take the time to have a conversation with them, they will understand." (V1, G4). Other assertions were more ambivalent, "... I don't know how to 
implement the education of the general public, but there has to be an education aspect there as well." (V4, G4).

Participants justified public concerns with calf welfare with concerns they shared as veterinarians, including poor hygiene or high rates of morbidity, by asking themselves, "... would I want to be bringing somebody [on this farm] and walk them around and would they be drinking milk after they've had this visit?" (V6, G1). Justifying public concerns also emerged for bull calf management and dehorning without pain control. Some participants aligned themselves with the public when describing welfare issues; for example, "... I think the public would have a big problem with, and I had a big problem with six years ago when bull calves were worth nothing ... the way that a number of our farmers were euthanizing the bull calves." (V2, G1).

To a lesser extent, participants discussed the media as an external pressure on shifting norms by increasing awareness, as described by one participant, "You're hearing about [calf welfare] more and more, and it's getting more face time, so people are going to pick up on it." (V3, G4). Avoiding negative media attention was also seen as a rationalization for improving problems such as bull calf management because, "... if the public was more aware of what was going on there, it's not probably going to make good press." (V1, G5).

Participants also described the economic pressures that influenced the shifting norms of calf management. The economic benefits of shifting from treating to preventing disease was argued to be why farmers were building facilities with improved ventilation, "... they realize that it's important, all those bottles of various long acting antibiotics, they're all expensive." (V1, G4). Economic pressures were noted for facilitating improved bull calf management, particularly when considering the opportunities for increased revenue from beef, and the drive toward increasing milk allowance during the preweaning period, which has been linked to increased milk production later in life. Participants also discussed the cost of management practices that promote welfare, notably providing pain relief during dehorning. Some participants indicated the cost of pain relief during dehorning was a barrier to the use of pain relief on farms. However, others disagreed, as this participant, who dehorns their client's calves, argued, "I think we focus on cost a lot ... but I would say ninety-five percent of my [farmers] don't even look at the [veterinary] bill at the end of the visit. They just want a good visit and good advice and good discussion." (V4, G4).

Internal Pressures to Change. Internal pressures to change calf management were seen by the participants as arising from farmers, veterinarians, and industry regulations. Pressures to improve welfare from colleagues who had recently graduated from veterinary school were seen to facilitate changing practices within the clinic. One participant described the pressure felt from colleagues to use pain relief during dehorning, "... the younger vets ... are pushing ... if I don't do the job well or [if] I do the same thing I did the last twenty years." (V6, G4). Participants also noted pressure coming from their clients as the impetus for them to rethink their role in promoting calf welfare, as described by this participant, "I had a [farmer] phone me on a Sunday morning for a calf with a broken leg, and I get out there and it was a back leg, and I lift up the leg to look at it, and said, '. . . this is a bull calf.' And the farmer, he made me feel so small. He said, 'So?... Fix the leg'." (V1, G2).

Pressure to improve welfare was also seen as a generational shift in farmer interest, leading to the observation that, "... we see a lot of the younger generation that's coming onto the farm that seem to really want to push the calf welfare issues." (V3, G4). Internal pressure for improving calf welfare was linked to the social influence that farmers have on each other. For example, one participant described the social pressure to provide good care to bull calves because farmers "... know that the calf [is] going to their neighbor and they don't want a bad reputation." (V1, G2). Social pressure among farmers was also noted for the use of pain relief during dehorning, as described by one participant:

"... one farmer [says], 'That it [using pain relief during dehorning] is the best thing we've ever started doing. I don't know why we didn't start doing that earlier.' And another farmer's like, 'Well, I still just do my own. I wait till they get this age and I gouge and hot iron them.' And [the first farmer] looks at him and [says], 'You-why? That is so stupid and it's hard ... I threw my gougers away years ago and I have never looked back ... What you're doing is wrong'." (V1, G2).

Regulations were described as an internal pressure on the shifting norms on calf management practices. Participants described regulations from within the dairy industry as forcing farmers to adopt practices aimed at improving welfare. Regulations were also considered as leverage to drive change on farms because they relieved the veterinarian of the burden of pressuring clients. When describing a national industry-based program, this participant explained how it would facilitate change in using pain relief during dehorning because, "... it helps us. ... They [farmers] really don't like this [regulation], but I use this as, 'you won't have the choice. I don't have the choice either, so let's do it right now and it's going to be okay'." (V6, G4). 


\section{Theme 3: How Veterinarians Consider Their Role in Improving Calf Welfare}

When participants described their role in improving calf welfare, they often placed themselves in a position of exerting social influence on each other, on their farmer clients, and on the public. As described by one participant: "I think we have a role, which is directly social" (V9, G3). They described different types of roles they embodied. including educator, motivator, and model, and associated strategies on how they could facilitate improved calf welfare.

Educator. Participants described themselves as educators to their farming clients, with an emphasis on building client capacity for technical skills such as using pain relief during dehorning: “... we've had tremendous uptake of the freezing [local anesthetic] and the pain management afterwards, and [farmers] are freezing themselves. We're not doing it. We teach them [how] to do it." (V3, G4). Educating clients also included improving awareness of problems not commonly discussed, such as measuring colostrum quality because, "... a lot of [our clients] don't know, so we're trying to make our clients more aware of the [colostrum] quality." (V6, G5).

Common strategies used by our participants to educate their clients included one-on-one meetings between the veterinarian and farmer, large group meetings at the clinic, and use of printed materials such as newsletters and written protocols. They also used informal discussions to promote improvements because this was seen to improve the relationship between the veterinarian and their client: "... I like to have a lunch meeting with [farmers]. That's the most valuable because then I can sit down and go through one topic with them and just hang out, and it's fun." (V2, G2).

Participants also saw themselves as educators of the public to address the public's lack of awareness of dairy farming practices as a root causes of concerns about calf welfare. Educating the public about dairy farming was viewed as a way to counteract negative views of large farms because "... people see grain bins with legs on them and think that that's a factory farm." (V4, G2). At times, the participants took a more introspective look at their role in educating the public, including linking trust and transparency because, "... our role is to be transparent and to show them or explain why we do that. Often when they understand why we do things, they're a little more open." (V1, G3).

Motivator. Participants also saw their role as motivating clients to use management practices that improve calf welfare because, "... sometimes when things are going well, then [farmers] get away from doing those things [that work well] ... all of a sudden, [they] fall back into some of the old problems, so you have to kind of keep hammering away that, you know, stay the course because that's what got you there." (V6, G1). Strategies used to motivate clients included collecting data. One participant described using data on serum total protein to motivate farmers to improve colostrum management, "... some [farmers] don't want to talk about [calf mortality] ... and then when you come back with some [total protein] numbers, say, 'Listen, I think you could do a much better job,' ... they usually [say], 'Okay, now, what should I do?"' (V6, G5). Participants also described how they used training procedures to motivate clients to improve calf welfare. This form of motivation emerged when participants described the positive effects of training clients to sedate calves before dehorning, "... one [farmer] was, like, 'This isn't even a challenge anymore' ... another [farmer's] like, 'This changed my life,' ... they love the pain mitigation and the sedation." (V4, G2).

Modeling. Participants considered themselves models for promoting calf welfare, reflecting how their own views and practices had influenced clients: "... if it doesn't seem important to the vets, then it's not going to seem important to the [farmer] lots of times." (V1, G4). Incorporating more services specifically for calves was a way that participants modeled prioritizing calf welfare. They described shifting their clinic's philosophy from treatment to prevention because, "... prevention is certainly a lot better than treatment and less time consuming." (V6, G1). Participants also described how they expanded services to include improved ways of diagnosing problems on farms by, "... collecting information, collecting samples, getting diagnostics done so that we can make a change quicker. I guess part of that comes from earlier days in practice where you tried this and then you tried that and then you tried this, and realizing that sometimes you got lucky, and often you didn't." (V4, G1). Some veterinarians discussed alternative treatment options that provided lower cost options for farmers such as using technicians to weigh calves and collect blood samples. Technicians were seen as a way of directing attention to any issues noticed during farm visits. In the words of one participant describing the calf technician's value in increasing the attention paid to calves, "... [the technicians are] really good with coming back and saying, 'Hey, you know, I noticed this. Next time you're out there, you really should bring it up." (V1, G5).

Accountability. Participants saw themselves as holding clients accountable for adopting and maintaining practices that promoted improved calf welfare. For example, holding clients accountable for calf health was described as, "... start[ing] early with good management ... You can't let it slide for those who really need it." 
(V8, G3). Participants used discussion to hold farmers accountable for calf management but specifically mentioning the need to talk to the people on farm who take care of the calves because, "... they seem to get the message better when you're talking directly to the person involved." (V4, G4). Protocols were used to hold farmers accountable for ensuring tasks were completed according to a standard, "... we have a few clients that have these lists [of questions] for their workers if they're feeding calves ...' 'Are they upright? Ears up? Snotty nose? Coughing?', just to remind them that it's not just feeding calves, it's looking at them." (V1, G4). Protocols also held the clinic veterinarians accountable for ensuring they were consistent about how they informed clients about procedures, "... we kind of all want to be giving the same information ... so we've come to an agreement that at least the minimum standard is this here and show it to them." (V1, G2).

\section{Theme 4: Normative Claims About Calf Welfare}

Participants made normative claims about how things should be with respect to calf welfare. This included how veterinarians should act as professionals, their moral judgments on topics related to calf welfare, and the ensuing dilemmas they experienced in addressing calf welfare.

Professional Duties. Descriptions of professional duties included obligations to both the calves and clients. Professional duties toward the calves were broadly characterized as taking a more active role in calf management, and participants identified themselves as having a prominent role in improving calf welfare arguing, "... with the training we get, our background and all we see, it's up to us to take a leadership role in the group." (V3, G3). Participants also identified a need to be transparent with their clients about their professional position on calf welfare, as described by this participant, "We have a responsibility to be categorical about what we believe." (V5, G3).

Claims were made about the need to start conversations about calf welfare, which were seen as a professional duty: "I think we're directly responsible for it. . . . If we don't start that conversation, who's going to?" (V6, G2). Others viewed this as the initial step in helping their clients think more critically about calf welfare, "... just starting the conversation ... getting our clients to start thinking about sort of the next step, beyond just health and hygiene, or nutrition of the calf, and just start to think about what's the next level or the next tier as far as overall health and welfare of the calves." (V1, G5).

Professional duties included linking good welfare and good financial health of their clients:
... if the welfare is that compromised, then they're going to be financially paying for it too. Like, the bad welfare equals bad efficiencies equals less profit. ... And if they don't understand that, that's our duty as veterinarians, $A$, to look out for the welfare of the animals, and B, look out for the welfare of the [farmer]. That's your livelihood. I think that's part of being a veterinarian, is standing up and telling them this is good or it's not good." (V3, G2).

Professional duties also included limiting choices for their clients; for example, in providing pain relief during dehorning, "I think the onus is on us. If you give them an option that sends a subliminal message that it is optional ... So, if we take on the responsibility to say, 'This is necessary, this is currently accepted and recommended...., it's the current standard,' ... the decision is taken away and it's not considered an option any more." (V5, G1). Participants were also concerned about what they thought would be their clients' interpretation of what motivated them to promote management practices that improved calf welfare, "... sometimes [farmers] interpret our recommendation [to treat pain] because I make money when I sell drugs." (V6, G4).

Moral Judgments. Participants expressed a variety of normative claims about the status of animals, calf welfare, on-farm practices, and people such as their farmer clients, the public, and other veterinarians. Claims about the moral status of calves as animals indicated 2 different types of views: animals were seen as either having an anthropocentric value (i.e., valuebased human use) or a nonanthropocentric value (i.e., value in and of itself, independent of human use value; see Morgan and McDonald, 2007). Anthropocentric values about the future use of the bull calves in the beef supply chain emerged as a reason for providing quality care after birth because, "... once [they] go to the sale, that's not the end of their lives. They still have to go on and be productive." (V4, G4). In contrast, nonanthropocentric values emerged as reasons for providing a bull calves with quality care after birth because, "it's alive." (V2, G1).

Normative claims about conceptions of animal welfare revealed diverse views. Some claims about calf welfare on farms were based on participant expectations of what are normal outcomes for calves. This judgment of normality included concerns about morbidity, as one participant described: "... it's not normal to have sick calves." (V10, G3). Participants reflected on their concept of calf welfare in relation to competing perspectives: "We are all animal welfarists, and I think all the [farmers] are animal welfarists. We just have different grades or different aspects of what animal welfare is." 
(V4, G4). Linking welfare and future production was discussed, as described by one participant: "... The not cared for calf doesn't do well, doesn't produce well ... Healthy calves are healthy cows." (V6, G2). However, concepts of welfare were also contextualized against evolving concerns, as described by one participant, "... the one thing I see that's going to change is that we think of welfare right now as a side effect of production ... I think eventually it's not going to be a side effect." (V1, $\mathrm{G} 2$ ).

Moral judgments about welfare emerged when describing a lack of action toward compromised welfare (e.g., pain or disease). Current practices did not meet some participants' criteria for good welfare for example, "... penetration of pain control, like [nonsteroidal anti-inflammatory drugs], is still not good enough." (V4, G5). When describing their concerns with calf welfare, participants in group 1 indicated a moral dimension to treating disease:

\section{Veterinarian 6: "... A calf untreated is..."}

\section{Veterinarian 4: "Cruel."}

Veterinarian 6: "... is not what we want to see."

Moral judgments about people included claims about the public, farmers, and veterinarians. Claims about the public were often linked to participants' perception that they were misinformed about the dairy industry leading to judgments that, "... [the public's] perception of animal welfare is skewed ... and probably wrong, mostly." (V2, G2).

Moral judgments about farmers revealed that participants had expectations about what should motivate their clients to improve calf welfare: "You shouldn't have to be losing a lot of calves to improve your calf health performance." (V6, G1). Values based on economics were seen in contrast to welfare for example, "I think we do have some [farmers] that are economic driven, but I think the vast majority just ... want to see [the calf] do well and they don't care if it costs two or four dollars more per animal." (V2, G4). Moral judgments also characterized farmers based on the compromised status of the calves, as one participant described, "I've seen facilities where every single calf had scours ... it was just terrible because their management of the cleanliness of the environment." (V4, G2).

Judgments about farmer willingness to change revealed that participants characterized farmers based on their receptivity to changes, as one participant indicated, "I think that's like everything, a good [farmer] is doing well with [making changes], and a bad [farmer] is more difficult for us." (V2, G4). Receptivity to change was also characterized as good in the context of generational differences between farmers, as one participant explained, "I'm kind of lucky because a lot of the farms that I work on today, it's the third generation I'm working with ... and they're progressive." (V6, G1). These judgments also demarcated what a good (farmer) does and how this should be promoted, as described with bull calf management:

"... [farmers] who... still make sure [the bull calf] gets all the colostrum that their heifers do, gives them a first defense bolus [immune system booster] because you never know what's going to happen... that's the [farmer] you'd like to hold up as an example for everyone else, the one that's doing the right thing." (V4, G1).

Finally, participants made moral judgments about the veterinary profession, including how they themselves may overlook calf welfare concerns. Some claims reflect how veterinarians need to change regarding how they communicate with clients, for example, "I think we've done really good [with] the health part of things, ... but we aren't so good at opening discussion on ... what's good welfare, socially for the calf, ... asking the [farmers], 'what do you think of hutches?', or, 'do you think they should have contact with each other?"' (V2, G4). Moral judgments about veterinarians also included claiming responsibility for a perceived lack of involvement with calves (as noted in the previous section), "I think that the only thing that stops us from becoming involved ourselves as vets is our lack of interest ... I think it is our fault if we are not more involved than that." (V9, G3).

Dilemmas. Participants' descriptions about addressing calf welfare could be characterized as moral dilemmas (when it is not clear what the right action is to take) or practical dilemmas (when it is clear what the right action is to take but it is difficult to take; Morgan and McDonald, 2007). Moral dilemmas occurred when the participants discussed balancing their professional duty to intervene and their financial responsibility to their clients. For example, when discussing using pain relief during dehorning, this participant offered, "I' $m$ probably one of the last guys to implement the pain management part of it, just because ... I'm thinking what the cost for the [farmer] is." (V1, G4). However, this same issue of providing pain relief was also characterized less clearly by some as a moral dilemma, indicating a shift in moral judgments about practices: "... we often, and I'm guilty of it, are wondering should we do it [provide pain relief] because it's going to cost more, 
but I think ..., if the visit cost four dollars a calf more, I'm not so sure at the end of the month they're going to notice that." (V4, G4).

Participants were concerned that a professional duty to take a more active role with calves, such as approaching their clients about welfare, put them at risk of potentially losing clients. As one participant stated: "I can preach many times but at some point, if I keep doing it I'll lose that client. Sometimes we're at the mercy of the client." (V4, G3).

Practical dilemmas related to improving calf welfare often involved the issue of time management. One participant described the perceived risk of upsetting clients by including calves into routine visits: "... if we go awry and then we end up with a huge herd health visit, and everything else gets delayed by an hour or an hour and a half, we'll have a lot of grumpy people at the end of the day." (V4, G4). Another practical dilemma was the perception that the farmers had other competing interests, as explained, "If the [farmer] perceives it as a problem, then you have their attention. But for the [farmer], if he's got other, bigger problems, then that is not significant to him at this time, and so it's very difficult to try and engage him in discussion." (V5, G1). Additionally, practical dilemmas emerged for how best to approach their clients to discuss calf welfare, "... a challenge [for me], is how to bring up a topic without being insulting, right? You don't want to [say], 'Hey, you're not doing it right'." (V2, G2).

\section{DISCUSSION}

Our results indicate that Canadian dairy cattle veterinarians identified many welfare issues for dairy calves, see these issues evolving as norms of calf management shift, identify their role as social in promoting improvements in calf welfare, and believe they have a professional responsibility to address calf welfare.

\section{How Dairy Cattle Veterinarians Conceptualize Welfare Issues}

Participants in our study readily identified diverse concerns about dairy calf welfare; given the nature of the veterinary profession, we were not surprised that they considered pain and disease to be major concerns. Veterinarian concerns with managing pain during dehorning (e.g., United States, Fajt et al., 2011; Denmark, Thomsen et al., 2012; Canada, Winder et al., 2016b) and managing calf disease (e.g., Canada, Bauman et al., 2016; the Netherlands, Boersema et al., 2013) is well documented. In contrast, veterinarian concerns regarding hunger and lack of nutrition in young calves-particularly associated with milk volumes- have received little attention in the literature. Vaarst et al. (2001) reported that veterinarian concerns about milk volumes were based on increased competition among calves housed in groups of varying age, resulting in some calves failing to receive adequate amounts of nutrition during the milk-fed period. The concern with nutrition and hunger in our focus groups indicates that this issue is a salient welfare concern for veterinarians, and we suggest that greater effort should be made to understand how veterinarians can promote increased milk allowance for calves in the preweaning period.

Veterinarian views about cow-calf separation vary. A North American study reported that veterinarians believed early separation of the cow and calf to be in the best interest of the calf (Ventura et al., 2013). In contrast, a study with Norwegian veterinarians found that keeping the cow and calf together was the most important welfare advantage in organic herds (Ellingsen et al., 2012). The difference in opinions about cowcalf separation could be attributed to the emphasis on natural behavior in organic dairy farming (Ellingsen et al., 2012). In agreement with Ventura et al. (2013), the participants in our study believed that cow-calf separation helped to maintain calf health.

Although participants in our study supported cowcalf separation, they believed this issue to be a common concern in the public's eye. Public concerns about cow-calf separation often center on natural behavior (Boogaard et al., 2010; Hötzel et al., 2017), and for some the practice is morally unjustified (Hötzel et al., 2017), indicating the concern is value-based. Participants in our study had nuanced views about the underlying reasons for why they thought cow-calf separation was a public concern; however, all groups felt that public education was the primary strategy to alleviate these concerns. Industry-based stakeholders' characterization of public concerns with animal welfare as symptomatic of a lack of knowledge about farming has been found in other studies of pig farmers (Bernard and de Cock Buning, 2013). Previous work has shown that educational efforts are likely to be ineffective in situations where disagreements are driven by differences in values (see Hansen et al., 2003). Ventura et al. (2016a) found that an educational intervention (touring a working dairy farm) accentuated naturalistic concerns, including those related to cow-calf separation. Participants in our study voiced their perception of public concerns about other issues such as barn hygiene, bull calf management, and lack of nutrition, but for these examples (in contrast to cow-calf separation), participants were in agreement that these were important issues to address on farms, not within the public sphere. This approach of shifting frames has been used in other studies with cattle veterinarians to identify a variety of concerns 
related to biosecurity on dairy farms (Shortall et al., 2016). By using the public's concerns to justify their own concerns regarding these practices (not including cow-calf separation), participants in our study shifted their frame of reference about calf welfare concerns, revealing attitudes more amenable to change.

Ventura et al. (2015) studied North American dairy industry stakeholders (including veterinarians) and identified the lack of prioritization of calves by farmers as an important concern (see also Mee, 2013). Participants in our study identified multiple reasons, including economics, for why calves may be a low priority for both farmers and their veterinarians. The influence of economics on how veterinarians approach welfare is context-dependent. Veterinarians may be unwilling to advise practices that improve health if they perceive their clients to be concerned with cost (Sayers et al., 2014; Shortall et al., 2016). Veterinarians may also overestimate the role that economic factors have on motivating behavioral change in farmers (Sorge et al., 2010). Specifically for calves, one study found that veterinarians were more concerned than farmers with the cost of treatment for pain relief for dehorning (Winder et al., 2016b). In our study, participants had divergent views on the extent that cost of pain relief was a barrier to adoption. Some felt the cost was prohibitive, whereas others felt the cost of pain relief during dehorning was a non-issue to farmers, who were more interested in how calves performed after the surgery and the value of the visit with their herd veterinarian.

Bull calf management practices on farms are not well documented (Winder et al., 2016a; Renaud et al., 2017). When discussed by our participants, their perceptions of the quality of bull calf care appeared contingent on economic factors such as the market value of bull calves and routine practices of shipping the bull calf off the farm shortly after birth. Risk factors contributing to bull calf mortality after arrival on veal farms (Winder et al., 2016a), and management practices on farm of origin (Renaud et al., 2017), indicate that the early rearing period for bull calves needs improvement. The concerns that arose during our study regarding poor nutrition and colostrum management of bull calves indicate that improving these practices would be supported by veterinarians. Our participants also provided examples of clients who provide adequate care for bull calves, suggesting that identifying mechanisms that encourage farmers to provide quality care for bull calves regardless of market value would be beneficial in improving calf welfare.

The trade-offs between socially housing calves and disease indicate that our participants align with other veterinarians in that they were primarily concerned with production-related issues (Verbeke, 2009), advocating for hygiene over social housing (commonly associated with automated milk feeders). This result suggests that educational efforts directed toward veterinarians should emphasize methods of maintaining high levels of health in social housing; for example, by promoting the use of pairs and small groups (reviewed by Costa et al., 2016). Given that the use of automated milk feeders for grouped calves is increasing (Medrano-Galarza et al., 2017), identifying ways to promote improved hygiene with this system is also required.

Veterinarians may perceive their lack of consensus about a conception of welfare as a barrier to welfare improvements on farms (Ventura et al., 2016b); however, as our study shows, what veterinarians believe matters for calf welfare relates to their position as a veterinarian. The perception of protecting the health of the calf is fundamental to how they view management practices on farms as either promoting or being detrimental to the welfare of the calf. For example, participants believed that practices that harmed calf health such as current bull calf management, poor colostrum management, and inadequate nutrition and hunger needed improvement. However, participants' views on changing management practices that they perceived to explicitly benefit health, such as cow-calf separation, appeared to be the least flexible. Additionally, beliefs about changing practices that did not explicitly link to calf health such as performing painful procedures without pain relief were less universal, suggesting that health concerns are prioritized over those of affective states (i.e., pain). Understanding veterinarian concepts of animal welfare is important for assessment (Meijboom, 2017); for example, focusing on improving hygiene in group housing systems or promoting veterinary advocacy for increased milk allowance in the preweaning period.

\section{The Role of the Veterinarian in Improving Calf Welfare}

The social influence of farmers and veterinarians on adoption of practices has been noted in other studies. Farmers indicate that veterinarians have an important role in advising clients on welfare concerns such as lameness (Kauppinen et al., 2010). Additionally, farmers can exert social pressure on each other to adopt management practices on farms for mastitis control (Swinkels et al., 2015). The influence of other farmers on calf rearing practices is likely context driven, based on the relationships that farmers have with each other and the specific practice of interest (Sumner et al., 2018).

Our participants indicated that they believe their role in improving calf welfare to be social and that improving communication with their clients and among 
each other is a way to exert this social influence. Participants described the importance of making time to talk to their clients about calf welfare and their overall farm goals; however, they also described approaches to improving welfare that focused on ensuring accountability and removing choice. These persuasive approaches can reinforce more typical advisor-client relationships, characterized as paternalistic, that pose barriers to improved communication because they overlook the farmer's perspective (Bard et al., 2017). We also found that participants in our study made efforts to acknowledge their clients' perspective on calf welfare. Participants acknowledged that engaging in conversation with their clients helped build their relationship, they recognized the need to ask their clients about how they felt about calf welfare topics such as social housing, and they believed that one of their roles in improving calf welfare was to motivate their clients, all of which suggest an understanding of the need to prioritize their clients' values. Individualized approaches toward advisement that consider the contextual implications for farmer decision-making are argued as essential for future success with veterinarian-farmer communication (Kristensen and Jakobsen, 2011).

Participants also differentiated between their client's willingness to improve calf welfare, evident in their descriptions that clients vary with willingness to change, that different generations of farmers have different values about welfare, and that understanding clients' priorities is not universal. Collectively, this suggests that how veterinarians approach their clients varies depending on the expected receptivity to improving calf welfare. Researchers have suggested that typologies based on farmer receptivity to information may be useful in guiding communication efforts to improve on-farm management (Jansen et al., 2010; Ritter et al., 2016). Additionally, evidence exists that veterinarians use some form of characterization to guide approaching their clients (Richens et al., 2016). Social pressure from veterinarians to improve calf welfare remains underexplored and we suggest the need for further work to identify how veterinarian perceptions of their role may shift, as do the norms of calf management, and their use of their social position to respond to these changing norms.

Our study provides evidence that Canadian dairy cattle veterinarians use a variety of strategies to improve calf welfare on farms in response to their perceptions of shifting norms of calf management. Ventura et al. (2016b) found that cattle veterinary practitioners and researchers self-identified as lacking knowledge on how to improve welfare, perhaps compromising their role. This lack of expertise can also be felt from the farmer's perspective. Studies have found that organic dairy farmers perceive that their veterinarian lacked relevant expertise needed for effective advising (Vaarst et al., 2006; Duval et al., 2017). The implication of offering atypical services for clients - in our case, practices that promote improvements in calf welfare - is that veterinarians require the appropriate training and knowledge. Participants in our study readily offered different strategies on how to improve calf welfare on farms, suggesting that this group of veterinarians was comfortable advising on this topic. The results of this study were based on discussions of participants who attended a veterinary continuing education workshop on cattle welfare, suggesting a selection bias toward veterinarians that were motivated to learn how to achieve improved outcomes, and may not reflect views of other veterinarians in Canada.

\section{The Responsibility of the Veterinarian to Improve Calf Welfare}

Veterinarian obligations to both animal patients and human clients are well described (see Morgan and McDonald, 2007; Meijboom, 2017). Veterinarian professional roles with the dairy cattle herd have focused on the health (LeBlanc et al., 2006) and reproductive performance (Mee, 2007) of the lactating dairy cow, suggesting an obligation more focused on the adult animals in the herd. Our study presents evidence that veterinarians believe they have a professional obligation to the dairy calf, placing the responsibility for addressing welfare concerns primarily in their realm of duties. Participants expressed both instrumental and intrinsic values about the moral status of calves, indicating that views are diverse and complex; however, they shared a sense of professional responsibility for the calf. At least one study has shown that dairy cattle veterinarians feel an obligation to treat and prevent pain, including the pain associated with dehorning (Fajt et al., 2011). Strong moral judgments in our study, such as the cruelty of failing to treat disease, illustrate participants' healthcentered conception of welfare. However, participants also made strong moral judgements about current milk feeding practices and bull calf euthanasia they deemed as wrong. We recommend further exploration of the range of moral judgments veterinarians make about calf welfare to better understand where veterinarians may be more likely to advocate for improvements.

Participants' discussions about their responsibility to their clients revealed a complex relationship of moral judgments and professional obligations. For some participants, professional obligations to the calf resulted in paternalistic advising approaches that limited their client's choices with respect to practices such as providing pain relief during dehorning. Other participants felt 
that their influence was more limited. Moral judgments about farmers typically characterized "good farmers" and "bad farmers" based on their willingness to change; the implication of how this affects a veterinarian's willingness to address calf welfare concerns should be considered. Some studies have found that veterinarian perceptions of what is important to the farmer can inhibit approaching a topic (Sayers et al., 2014; Shortall et al., 2016). Veterinarians have also admitted that they are often overly critical of farmers, citing their own perceptions of their clients' lack of education and poor understanding of economic factors as barriers to maintaining a relationship with them (Ventura et al., 2016b). Claims about what is important to farmers can also have negative outcomes from the farmers' perspective. Derks et al. (2012) found that only half of the surveyed farmers thought their veterinarian was aware of their farm goals, and almost a quarter felt that they were ignored. These examples, and the results of our study, suggest that there are missed opportunities to improve welfare based on veterinarian assumptions about clients and calf welfare.

Balancing conflicting responsibilities has been described in a few studies with cattle veterinarians (Higgins et al., 2013; Ventura et al., 2016b). Similar to those described by participants in our study, these responsibilities included those to the animals, to the client, and to the clinic. For practical dilemmas, there remain concerns about understanding each actor's perspective on the value of an action. For dairy cattle veterinarians, understanding their clients' values about veterinary services can help reduce practical dilemmas. For example, Bell et al. (2006) found that farmers' failure to see the benefits of adopting herd health plans was related to bureaucratic tasks and time constraints. Participants in our study indicated that navigating client schedules, recognizing client priorities, and, at times, limiting choices could reduce barriers to addressing calf welfare.

Descriptions of moral dilemmas in our study included balancing a duty to treat pain during dehorning with a professional responsibility for their client's financial health. Other studies have identified discrepancies in the level of pain that veterinarians attribute to dehorning and the extent to which they treat the pain (Huxley and Whay, 2006; Fajt et al., 2011). Winder et al. (2016b) found that more Canadian veterinarians now treat dehorning pain out of concern for the calf; however, the same study found that the primary reason that some veterinarians did not treat pain was concern over treatment costs. Some participants in our study identified a generational effect in both farmer and veterinarian values, suggesting that moral dilemmas involved in improving calf welfare may shift as farmers' and veterinarians' values shift, notably in treating pain as a moral duty for veterinarians and recognizing that this is also important to their clients. Promoting dialog between veterinarians and clients about professional and personal values can help reduce moral dilemmas by establishing boundaries for providing veterinary services (Morgan and McDonald, 2007). Self-reflection within the veterinary profession has been suggested as a starting point to address the tension inherent in the dual obligation to clients and animals (Morgan and McDonald, 2007; Meijboom, 2017). In addition to self-reflection, we suggest promoting dialog within the clinic on the evolving expectations of providing services related to calf welfare, which might reduce the challenge of weighing the professional duties to the calf against those of the farmer.

\section{CONCLUSIONS}

Our study provides a description of the views of Canadian dairy cattle veterinarians regarding calf welfare. Veterinarians share concerns beyond those previously reported relating to health and growth and feel obligated to do more for calves. We provide evidence that veterinarians are concerned about educating, motivating, and holding their clients responsible for calf welfare improvements. The views described in this study do not represent all Canadian veterinarians, and further work using in-depth discussion with different groups of veterinarians could provide additional information about the potential influence of cultural context that shapes how veterinarians view calf welfare. We believe future use of guided discussions such as focus groups can promote dialog on topics such as calf welfare, where the boundaries demarcating responsibility are shifting and personal values and professional duties are evolving.

\section{ACKNOWLEDGMENTS}

We express warm gratitude to Naseeb Bolduc (University of British Columbia, Vancouver, BC, Canada) and Adam Shriver (University of Oxford, Oxford, UK) for their help with parts of the data analysis. We are grateful to Hannah Wittman and Daniel M. Weary (University of British Columbia, Vancouver BC, Canada) for their comments on a previous version of this manuscript. Funding for Christine Sumner was provided by the University of British Columbia's $4 \mathrm{YF}$ doctoral fellowship program. This research was made possible, in part, by a generous donation from Vetoquinol Canada (Lavaltrie, Québec, Canada). 


\section{REFERENCES}

Bard, A. M., D. C. J. Main, A. M. Haase, H. R. Whay, E. J. Roe, and K. K. Reyher. 2017. The future of veterinary communication: Partnership or persuasion? A qualitative investigation of veterinary communication in the pursuit of client behavior change. PLoS One 12:e0171380.

Bauman, C. A., H. W. Barkema, J. Dubuc, G. P. Keefe, and D. F. Kelton. 2016. Identifying management and disease priorities of Canadian dairy industry stakeholders. J. Dairy Sci. 99:10194-10203.

Becker, J., M. Reist, K. Friedli, D. Strabel, M. Wüthrich, and A. Steiner. 2013. Current attitudes of bovine practitioners, claw-trimmers and farmers in Switzerland to pain and painful interventions in the feet in dairy cattle. Vet. J. 196:467-476.

Bell, N. J., D. C. J. Main, H. R. Whay, T. G. Knowles, M. J. Bell, and A. J. F. Webster. 2006. Herd health planning: Farmers' perceptions in relation to lameness and mastitis. Vet. Rec. 159:699-705.

Bernard, M., and T. de Cock Buning. 2013. Exploring the potential of Dutch pig farmers and urban-citizens to learn through frame reflection. J. Agric. Environ. Ethics 26:1015-1036.

Boersema, J. S. C., J. P. T. M. Noordhuizen, and J. J. Lievaart. 2013. Hazard perception of Dutch farmers and veterinarians related to dairy young stock rearing. J. Dairy Sci. 96:5027-5034.

Boogaard, B. K., B. B. Bock, S. J. Oosting, and E. Krogh. 2010. Visiting a farm: An exploratory study of the social construction of animal farming in Norway and The Netherlands based on sensory perception. Int. J. Sociol. Agric. Food 17:24-50.

Broughan, J. M., D. Maye, P. Carmody, L. A. Brunton, A. Ashton, W. Wint, N. Alexander, R. Naylor, K. Ward, A. V. Goodchild, S. Hinchliffe, R. D. Eglin, P. Upton, R. Nicholson, and G. Enticott. 2016. Farm characteristics and farmer perceptions associated with bovine tuberculosis incidents in areas of emerging endemic spread. Prev. Vet. Med. 129:88-98.

Costa, J. H. C., M. A. G. von Keyserlingk, and D. M. Weary. 2016. Invited review: Effects of group housing of dairy calves on behavior, cognition, performance, and health. J. Dairy Sci. 99:2453-2467.

Derks, M., L. M. A. van de Ven, T. van Werven, W. D. J. Kremer, and H. Hogeveen. 2012. The perception of veterinary herd health management by Dutch dairy farmers and its current status in the Netherlands: A survey. Prev. Vet. Med. 104:207-215.

Duval, J. E., N. Bareille, C. Fourichon, A. Madouasse, and M. Vaarst. 2016. Perceptions of French private veterinary practitioners on their role in organic dairy farms and opportunities to improve their advisory services for organic dairy farmers. Prev. Vet. Med. 133:10-21.

Duval, J. E., N. Bareille, C. Fourichon, A. Madouasse, and M. Vaarst. 2017. How can veterinarians be interesting partners for organic dairy farmers? French farmers' point of views. Prev. Vet. Med. 146:16-26.

Ellingsen, K., C. M. Mejdell, and B. Hansen. 2012. Veterinarians' and agricultural advisors' perception of calf health and welfare in organic dairy production in Norway. Org. Agric. 2:67-77.

Fajt, V. R., S. A. Wagner, and B. Norby. 2011. Analgesic drug administration and attitudes about analgesia in cattle among bovine practitioners in the United States. J. Am. Vet. Med. Assoc. 238:755-767.

Fraser, D., D. M. Weary, E. A. Pajor, and B. N. Milligan. 1997. A scientific conception of animal welfare that reflects ethical concerns. Anim. Welf. 6:187-205.

Friedman, D. B., C. P. Kanwat, M. L. Headrick, N. J. Patterson, J. C. Neely, and L. U. Smith. 2007. Importance of prudent antibiotic use on dairy farms in South Carolina: A pilot project on farmers' knowledge, attitudes and practices. Zoonoses Public Health 54:366-375.

Garforth, C. J. 2011. Effective communication to improve udder health: Can social science help? Page 55-66 in Udder Health and Communication. H. Hogeveen and T. G. J. M. Lam, ed. Wageningen Academic Publishers, Wageningen, the Netherlands.

Guest, G., K. M. MacQueen, and E. E. Namey. 2014. Applied Thematic Analysis. Sage, Thousand Oaks, CA.
Hansen, J., L. Holm, L. Frewer, P. Robinson, and P. Sandøe. 2003. Beyond the knowledge deficit: Recent research into lay and expert attitudes to food risks. Appetite 41:111-121.

Higgins, H. M., E. Ferguson, R. F. Smith, and M. J. Green. 2013. Using hormones to manage dairy cow fertility: The clinical and ethical beliefs of veterinary practitioners. PLoS One 8:e62993.

Hötzel, M. J., C. S. Cardoso, A. Roslindo, and M. A. G. von Keyserlingk. 2017. Citizen views on the practices of zero-grazing and cowcalf separation in the dairy industry: Does providing information increase acceptability? J. Dairy Sci. 100:4150-4160.

Huxley, J. N., and H. R. Whay. 2006. Current attitudes of cattle practitioners to pain and the use of analgesics in cattle. Vet. Rec. 159:662-668.

Jansen, J., C. D. M. Steuten, R. J. Renes, N. Aarts, and T. J. G. M. Lam. 2010. Debunking the myth of the hard-to-reach farmer: Effective communication on udder health. J. Dairy Sci. 93:1296-1306.

Kauppinen, T., A. Vainio, A. Valros, H. Rita, and K. M. Vesala. 2010. Improving animal welfare: Qualitative and quantitative methodology in the study of farmers' attitudes. Anim. Welf. 19:523-536.

Kristensen, E., and E. B. Jakobsen. 2011. Challenging the myth of the irrational dairy farmer; understanding decision-making related to herd health. N. Z. Vet. J. 59:1-7.

Lastein, D. B., M. Vaarst, and C. Enevoldsen. 2009. Veterinary decision making in relation to metritis - A qualitative approach to understand the background for variation and bias in veterinary medical records. Acta Vet. Scand. 51:36.

LeBlanc, S. J., K. D. Lissemore, D. F. Kelton, T. F. Duffield, and K. E. Leslie. 2006. Major advances in disease prevention in dairy cattle. J. Dairy Sci. 89:1267-1279.

Lund, V., G. Coleman, S. Gunnarsson, M. C. Appleby, and K. Karkinen. 2006. Animal welfare science- Working at the interface between the natural and social sciences. Appl. Anim. Behav. Sci. 97:37-49.

Medrano-Galarza, C., S. J. LeBlanc, T. J. DeVries, A. Jones-Bitton, J. Rushen, A. M. de Passillé, and D. B. Haley. 2017. A survey of dairy calf management practices among farms using manual and automated milk feeding systems in Canada. J. Dairy Sci. 100:6872-6884.

Mee, J. F. 2007. The role of the veterinarian in bovine fertility management on modern dairy farms. Theriogenology 68:S257-S265.

Mee, J. F. 2013. Why do so many calves die on modern dairy farms and what can we do about calf welfare in the future? Animals (Basel) 3:1036-1057.

Meijboom, F. L. 2017. More than just a vet? Professional integrity as an answer to the ethical challenges facing veterinarians in animal food production. Food Ethics 1:209-220.

Misch, L. J., T. F. Duffield, S. T. Millman, and K. D. Lissemore. 2007. An investigation into the practices of dairy producers and veterinarians in dehorning dairy calves in Ontario. Can. Vet. J. 48:1249-1254.

Morgan, C. A., and M. McDonald. 2007. Ethical dilemmas in veterinary medicine. Vet. Clin. North Am. Small Anim. Pract. 37:165179

Powell, R. A., and H. M. Single. 1996. Focus groups. Int. J. Qual. Health Care 8:499-504.

Renaud, D. L., T. F. Duffield, S. J. LeBlanc, D. B. Haley, and D. F. Kelton. 2017. Management practices for male calves on Canadian dairy farms. J. Dairy Sci. 100:6862-6871.

Richens, I. F., P. Hobson-West, M. L. Brennan, Z. Hood, J. Kaler, M. Green, N. Wright, and W. Wapenaar. 2016. Factors influencing veterinary surgeons' decision-making about dairy cattle vaccination. Vet. Rec. 179:410.

Rimal, R. N., and K. Real. 2005. How behaviors are influenced by perceived norms. A test of the theory of normative social behavior. Communic. Res. 32:389-414.

Ritter, C., J. Jansen, S. Roche, D. F. Kelton, C. L. Adams, K. Orsel, R. J. Erskine, G. Benedictus, T. J. G. M. Lam, and H. W. Barkema. 2017. Invited review: Determinants of farmers' adoption of management-based strategies for infectious disease prevention and control. J. Dairy Sci. 100:3329-3347. 
Ritter, C., J. Jansen, K. Roth, J. P. Kastelic, C. L. Adams, and H. W. Barkema. 2016. Dairy farmers' perceptions toward the implementation of on-farm Johne's disease prevention and control strategies. J. Dairy Sci. 99:9114-9125.

Ritter, C., G. P. S. Kwong, R. Wolf, C. Pickel, M. Slomp, J. Flaig, S. Mason, C. L. Adams, D. F. Kelton, J. Jansen, J. De Buck, and H. W. Barkema. 2015. Factors associated with participation of Alberta dairy farmers in a voluntary, management-based Johne's disease control program. J. Dairy Sci. 98:7831-7845.

Sayers, R. G., M. Good, and G. P. Sayers. 2014. A survey of biosecurity-related practices, opinions and communications across dairy farm veterinarians and advisors. Vet. J. 200:261-269.

Shortall, O., A. Ruston, M. Green, M. Brennan, W. Wapenaar, and J. Kaler. 2016. Broken biosecurity? Veterinarians' framing of biosecurity on dairy farms in England. Prev. Vet. Med. 132:20-31.

Sorge, U., D. Kelton, K. Lissemore, A. Godkin, S. Hendrick, and S. Wells. 2010. Attitudes of Canadian dairy farmers toward a voluntary Johne's disease control program. J. Dairy Sci. 93:1491-1499.

Sumner, C. L., M. A. G. von Keyserlingk, and D. M. Weary. 2018. How benchmarking motivates farmers to improve dairy calf management. J. Dairy Sci. 101:3323-3333.

Swinkels, J. M., A. Hilkens, V. Zoche-Golob, V. Krömker, M. Buddiger, J. Jansen, and T. J. G. M. Lam. 2015. Social influences on the duration of antibiotic treatment of clinical mastitis in dairy cows. J. Dairy Sci. 98:2369-2380.

Thomsen, P. T., I. Anneberg, and M. S. Herskin. 2012. Differences in attitudes of farmers and veterinarians towards pain in dairy cows. Vet. J. 194:94-97.

Tremetsberger, L., and C. Winckler. 2015. Effectiveness of animal health and welfare planning in dairy herds: A review. Anim. Welf. 24:55-67.

Vaarst, M., L. Alban, L. Mogensen, S. M. Thamsborg, and E. S. Kristensen. 2001. Health and welfare in Danish dairy cattle in the tran- sition to organic production: Problems, priorities and perspectives. J. Agric. Environ. Ethics 14:367-390.

Vaarst, M., T. W. Bennedsgaard, I. Klaas, T. B. Nissen, S. M. Thamsborg, and S. Østergaard. 2006. Development and daily management of an explicit strategy of nonuse of antimicrobial drugs in twelve Danish organic dairy herds. J. Dairy Sci. 89:1842-1853.

Ventura, B. A., M. A. G. von Keyserlingk, C. A. Schuppli, and D. M. Weary. 2013. Views on contentious practices in dairy farming: The case of early cow-calf separation. J. Dairy Sci. 96:6105-6116.

Ventura, B. A., M. A. G. von Keyserlingk, and D. M. Weary. 2015. Animal welfare concerns and values of stakeholders within the dairy industry. J. Agric. Environ. Ethics 28:109-126.

Ventura, B. A., M. A. G. von Keyserlingk, H. Wittman, and D. M. Weary. 2016a. What difference does a visit make? Changes in animal welfare perceptions after interested citizens tour a dairy farm. PLoS One 11:e0154733.

Ventura, B. A., D. M. Weary, A. S. Giovanetti, and M. A. G. von Keyserlingk. 2016b. Veterinary perspectives on cattle welfare challenges and solutions. Livest. Sci. 193:95-102.

Verbeke, W. 2009. Stakeholder, citizen and consumer interests in farm animal welfare. Anim. Welf. 18:325-333.

Winder, C. B., D. F. Kelton, and T. F. Duffield. 2016a. Mortality risk factors for calves entering a multi-location white veal farm in Ontario, Canada. J. Dairy Sci. 99:10174-10181.

Winder, C. B., S. J. LeBlanc, D. B. Haley, K. D. Lissemore, M. A Godkin, and T. F. Duffield. 2016b. Practices for the disbudding and dehorning of dairy calves by veterinarians and dairy producers in Ontario, Canada. J. Dairy Sci. 99:10161-10173.

Wolf, C. A., G. T. Tonsor, G. S. McKendree, D. U. Thomson, and J. C. Swanson. 2016. Public and farmer perceptions of dairy cattle welfare in the United States. J. Dairy Sci. 99:5892-5903. 